\title{
The glycolipid of Halobacterium sodomense
}

\author{
A. Trincone, ${ }^{1}$ B. Nicolaus, ${ }^{1}$ L. Lama, ${ }^{1}$ M. De Rosa, ${ }^{1,2}$ A. Gambacorta ${ }^{1}$ and W. D. Grant ${ }^{3 *}$ \\ ${ }^{1}$ Istituto di Clinica di Molecole di Interesse Biologica, CNR, Via Toiana, Arco Felice, Napoli, Italy \\ ${ }^{2}$ Istituto di Biochimica delle Macromolecole dell'Università, Naples, Italy \\ ${ }^{3}$ Department of Microbiology, University of Leicester, Leicester LE1 9HN, UK
}

(Received 24 April 1990; revised 6 July 1990; accepted 24 July 1990)

\begin{abstract}
The glycolipid of the halophilic archaeobacterium Halobacterium sodomense has been analysed by spectroscopic methods including ${ }^{13} \mathrm{C}$ NMR to establish structural details, and has been shown to be a sulphated $C_{20}, C_{20}$ mannosyl glucosyl diether glycerol. This structure differs from all other known halobacterial glycolipids in having a sulphate substitution at C-2 of the mannose residue, and in being an $\alpha$-D-(1 $\rightarrow 4)$-linked disaccharide.
\end{abstract}

\section{Introduction}

The taxonomy of the red archaeobacterial halophiles (halobacteria) is based largely on chemotaxonomic markers, rather than standard biochemical tests (Grant $\&$ Larsen, 1989a). In particular, the use of polar lipid composition to assign isolates to particular groups of genera has proved of considerable value. All halobacteria examined to date contain $\mathrm{C}_{20}, \mathrm{C}_{20}$ (diphytanyl), $\mathrm{C}_{20}, \mathrm{C}_{25}$ (phytanyl-sesterterpanyl) or $\mathrm{C}_{25}, \mathrm{C}_{25}$ (disesterterpanyl) diether analogues of phosphatidyl glycerol (PG) and phosphatidyl glycerol phosphate (PGP). The presence or absence of phosphatidyl glycerol sulphate (PGS) and the structure(s) of any glycolipid(s) present define groups that are supported by $16 \mathrm{~S}$ rRNA/DNA hybridization (Ross \& Grant, 1985). Thus, Natronobacterium and Natronococcus spp. lack PGS and glycolipids, Halobacterium spp. are characterized by sulphated forms of triglycosyl (S-TGD-1) and tetraglycosyl (S-TeGD) lipids, Haloferax spp. by a sulphated diglycosyl lipid (SDGD-1) and Haloarcula spp. by a non-sulphated triglycosyl lipid (TGD-2) (Grant \& Larsen, 1989b, $c$; Larsen \& Grant, 1989; Grant, 1989a, b). All of the glycolipids characterized to date are derived from a basic $\alpha$-D-mannosyl $\alpha(1 \rightarrow 2)-\alpha$-D-glucosyl diphytanyl glycerol, by substitution of sugar or sulphate groups at the $\mathrm{C} 3$ or C6 positions of the mannose residue (Fig. 1).

The type strains of the organisms named as Halobacterium saccharovorum, Halobacterium trapanicum and

\footnotetext{
Abbreviations: FAB, fast atom bombardment; PG, phosphatidyl glycerol; PGP, phosphatidyl glycerol phosphate; PGS, phosphatidyl glycerol sulphate.
}

Halobacterium sodomense have all been considered in the past to be members of the genus Halobacterium as defined at that particular time. However, $16 \mathrm{~S}$ rRNA/DNA hybridization studies have shown that these strains comprise a relatively diverse taxon distinct from the genus Halobacterium as currently defined (Ross

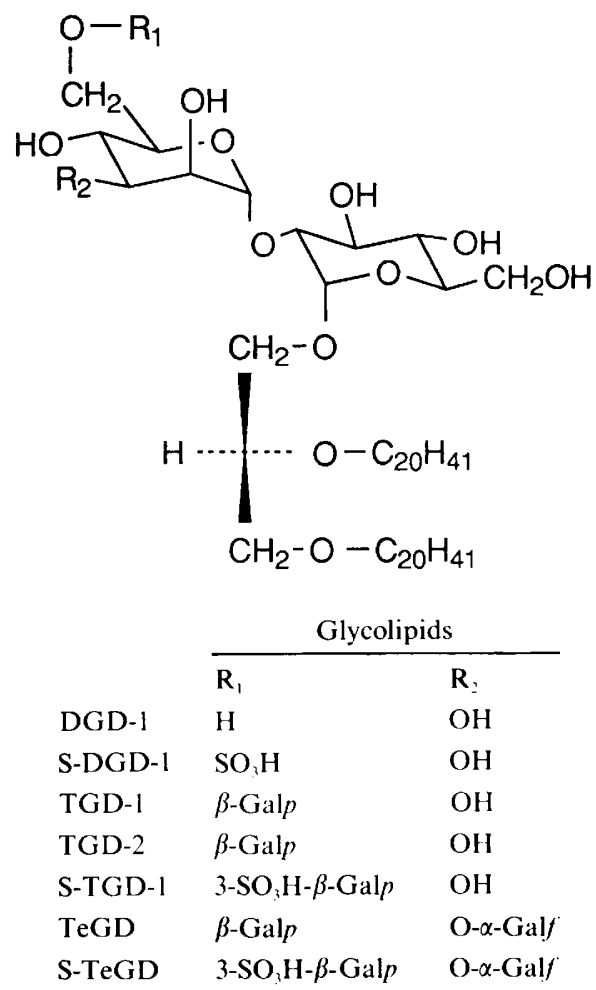

Fig. 1. Structural relationships of glycolipids based on $\alpha$-D-mannosyl $\alpha(1 \rightarrow 2)-\alpha$-D-glycosyl diphytanyl glycerol. 
\& Grant, 1985; Larsen \& Grant, 1989). These halobacteria also comprise the only group showing dam methylation of DNA (Lodwick et al., 1986). Immunological evidence does not support any close relationship between $\mathrm{Hb}$. saccharovorum and the type species of the genus Halobacterium (Conway de Macario et al., 1986) and these organisms also have different classes of fructose biphosphate aldolases (Dhar \& Altekar, 1986). However $H b$. saccharovorum, $H b$. sodomense and $H b$. trapanicum are not particularly closely related, since $H b$. saccharovorum shows only $45 \%$ DNA/DNA homology with $H b$. sodomense and $52 \%$ homology with $H b$. trapanicum (Ross \& Grant, 1985). Accordingly, these three organisms are treated as species incertae sedis in the latest edition of Bergey's Manual (Larsen \& Grant, 1989), where it is considered premature to activate the suggestion of Grant \& Ross (1986) that these organisms merit reclassification as separate species within a new genus.

There has also been some doubt over the polar lipid composition of these organisms, in particular the structure of the single glycolipid possessed by each strain. Recently, the glycolipid of $\mathrm{Hb}$. saccharovorum has been shown to be S-DGD-1 (Lanzotti et al., 1988). The glycolipid of $\mathrm{Hb}$. trapanicum co-chromatographs with that of $H b$. saccharovorum in several solvent systems (unpublished results), but the glycolipid of $\mathrm{Hb}$. sodomense undoubtedly shows different chromatographic behaviour (Torreblanca et al., 1986).

We report here the detailed characterization of the glycolipid of $\mathrm{Hb}$. sodomense.

\section{Methods}

Strain and culture conditions. The type strain of $\mathrm{Hb}$. sodomense (ATCC 33755) was grown in liquid shake culture in the medium described by Oren (1983). Cells were harvested in the late exponential phase of growth by centrifugation, washed with a basal salt solution (the growth medium without organic components) and lyophilized.

Extraction and isolation of lipids. Lyophilized cells $(6 \mathrm{~g})$ were extracted continuously by Soxhlet for $12 \mathrm{~h}$ with $\mathrm{CHCl}_{3} /$ methanol $(1: 1$, $\mathrm{v} / \mathrm{v})$ and then with methanol/ $\mathrm{H}_{2} \mathrm{O}(1: 1, \mathrm{v} / \mathrm{v})$. The extracts were pooled and evaporated under vacuum. Total lipid extract $(700 \mathrm{mg})$, dissolved in $20 \mathrm{ml} \mathrm{CHCl} 3 / \mathrm{methanol} / \mathrm{H}_{2} \mathrm{O}(65: 25: 4$, by vol.), was mixed with $5 \mathrm{~g}$ silica gel (Kieselgel 70-230 mesh, Merck) and dried; the dry material was added to the top of silica gel column $(40 \mathrm{~cm} \times 10 \mathrm{~mm}, \mathrm{i}$.d.). The column was eluted with 31 of a step gradient of $0-50 \%(\mathrm{v} / \mathrm{v})$ methanol in $\mathrm{CHCl}_{3}$ in $5 \%$ increments ( $250 \mathrm{ml}$ for each gradient step). All the lipids eluted were further purified by preparative TLC in $\mathrm{CHCl}_{3} /$ meth anol $/ \mathrm{H}_{2} \mathrm{O}(65: 25: 4$, by vol.).

Degradation procedures. Solvolysis of glycolipid was done in dioxane/pyridine $(1: 1, \mathrm{v} / \mathrm{v})$ at $100^{\circ} \mathrm{C}$ for $2 \mathrm{~h}$. After cooling, $\mathrm{H}_{2} \mathrm{O}$ was added and the solution extracted with butan-1-ol. The butanolic phase was washed with $\mathrm{H}_{2} \mathrm{O}$ and dried.

Acid hydrolysis was carried out in $2 \mathrm{M}-\mathrm{HCl}$ at $100^{\circ} \mathrm{C}$ for $6 \mathrm{~h}$. Hydrolysed products, after drying, were extracted with $\mathrm{CHCl}_{3}$ and the residue was dissolved in $\mathrm{H}_{2} \mathrm{O}$. The $\mathrm{CHCl}_{3}$ - and $\mathrm{H}_{2} \mathrm{O}$-soluble fractions were examined chromatographically.

Permethylation was carried out using the procedures of Wagner \& Seligmann (1973).

Acid methanolysis of permethylated glycolipid was done in $1 \mathrm{M}-\mathrm{HCl}$ in methanol at $100{ }^{\circ} \mathrm{C}$ for $3 \mathrm{~h}$.

Chromatographic procedures. TLC was performed on $0.25 \mathrm{~mm}$ layers of silica gel F254 (Merck) activated at $100^{\circ} \mathrm{C}$ for $2 \mathrm{~h}$. Solvents included: $\mathrm{CHCl}_{3} /$ methanol/ $\mathrm{H}_{2} \mathrm{O}(65: 25: 4$, by vol. $)$ and $\mathrm{CHCl}_{3} /$ methanol $/ \mathrm{CH}_{3} \mathrm{COOH} / \mathrm{H}_{2} \mathrm{O}(85: 22 \cdot 5: 10: 4$, by vol) for complex lipids: $\mathrm{CHCl}_{3} /$ diethyl ether $(9: 1, \mathrm{v} / \mathrm{v})$ for 2,3-di-O-phytanyl-sn-glycerol; butan-1-ol/ $\mathrm{CH}_{3} \mathrm{COOH} / \mathrm{H}_{2} \mathrm{O}(60: 20: 20$, by vol.) for glucose and mannose; $\mathrm{CHCl}_{3} /$ methanol $(97: 3, \mathrm{v} / \mathrm{v})$ for permethylated sugars. Compounds were detected either by exposure to $I_{2}$ vapour, or by spraying with $0.1 \% \mathrm{Ce}\left(\mathrm{SO}_{4}\right)_{2}$ in $1 \mathrm{M}-\mathrm{H}_{2} \mathrm{SO}_{4}$ followed by heating at $150^{\circ} \mathrm{C}$ for $5 \mathrm{~min}$. Specific reagents included the Dittmer and Lester reagent for phospholipids and $\alpha$-naphthol $/ \mathrm{H}_{2} \mathrm{SO}_{4}$ for glycolipids (Kates, 1986).

HPLC separation of the hexoses was done on an $\mathrm{NH}_{2}$-bonded reverse-phase Carbohydrate Analysis column $(30 \mathrm{~cm} \times 3.9 \mathrm{~mm}$ i.d.) (Waters Associates) using as solvent $\mathrm{CH}_{3} \mathrm{CN} / \mathrm{H}_{2} \mathrm{O}(80: 20, \mathrm{v} / \mathrm{v})$ at a flow rate of $1 \mathrm{ml} \mathrm{min}^{-1}$ with a Waters Associates apparatus; eluants from the column were detected by differential refractometry.

GLC of permethylated sugar was carried out on a glass column $(2 \mathrm{~mm} \times 2 \mathrm{~m}$ ) packed with $20 \%$ butan-1,4-diol succinate on Chromosorb WAW, with a column temperature of $155^{\circ} \mathrm{C}$ and $\mathrm{N}_{2}\left(1 \mathrm{~kg} \mathrm{~cm}^{-2}\right)$ as carrier gas (Yahara et al., 1977).

Mass spectrometry (MS). A Kratos MS-50 instrument equipped with a Kratos fast atom bombardment (FAB) source was used. The positive FAB mass spectra were obtained by dissolving the samples in a glycerol matrix, adding $0.1 \%$ sodium acetate in methanol to the probe prior to bombardment with argon atoms of kinetic energy equivalent to 2$6 \mathrm{keV}$. The negative FAB mass spectra were obtained as described for the positive FAB, without the addition of sodium acetate.

NMR spectroscopy. Samples for NMR spectroscopy were prepared by dissolving the lipid in $0.5 \mathrm{ml} \mathrm{C} \mathrm{C}^{2} \mathrm{HCl}_{3} / \mathrm{C}^{2} \mathrm{H}_{3} \mathrm{O}^{2} \mathrm{H}(7: 3, \mathrm{v} / \mathrm{v})$ or deuterobenzene- $\mathrm{d}_{6} / \mathrm{C}^{2} \mathrm{H}_{3} \mathrm{O}^{2} \mathrm{H}(1: 1, \mathrm{v} / \mathrm{v})$.

All the ${ }^{13} \mathrm{C}$ NMR spectra were run at $125 \mathrm{MHz}$ on a Bruker WH-500 spectrometer at room temperature, using trimethylsilane as an internal standard. Analyses of multiplicities were achieved by DEPT experiments performed using polarization transfer pulses of $90^{\circ}$ and $135^{\circ}$, respectively, obtaining in the first case only signals for methine groups and in the other case positive signals for methine and methyl groups and negative signals for methylene groups.

IR spectra. IR spectra were recorded at room temperature using an FT-IR Bio-Rad spectrophotometer.

Optical rotations. Optical rotations were measured at room temperature using a Perkin Elmer 141 polarimeter.

\section{Results and Discussion}

All the lipids eluted from the silica gel column were further purified by preparative TLC and identified by analytical TLC in comparison with authentic samples and by specific staining tests.

The complex lipids of $H b$. sodomense were PG (13\% of the total lipid extract), PGP (60\%), PGS (3\%) and an unknown glycolipid $(22 \%)$.

The glycolipid eluted from the silica gel column with $\mathrm{CHCl}_{3} /$ methanol $(80: 20, \mathrm{v} / \mathrm{v})$ had an $R_{\mathrm{F}}$ of 0.35 in 
$\mathrm{CHCl}_{3} /$ methanol/ $\mathrm{H}_{2} \mathrm{O}(65: 25: 4$, by vol. $)$, different from that of the glycolipid of $H b$. saccharovorum (0.4) (Lanzotti et al., 1988). It responded to sugar reagent and had an $[\alpha]_{D}$ value of 26.4 in $\mathrm{CHCl}_{3} /$ methanol $(1: 1, \mathrm{v} / \mathrm{v})$.

The IR spectrum of the compound in liquid film was similar to that reported for the glycolipid of $H b$. saccharovorum, particularly a broad band at $1250 \mathrm{~cm}^{-1}$ $\left(\mathrm{S}=\mathrm{O}\right.$ group) and an absorption band at $830 \mathrm{~cm}^{-1}(\mathrm{~S}-$ $\mathrm{O}-\mathrm{C}$ ) indicating the presence of sulphate.

Positive FAB mass spectra of the compound gave a molecular ion peak at $m / z 1078\left(\mathrm{M}^{+}+\mathrm{Na}^{+}\right)$while that of the compound obtained after solvolysis in dioxane/pyridine gave a molecular ion at $m / z 999\left(\mathrm{M}^{+}+\mathrm{Na}^{+}\right)$, thus establishing that the glycolipid possessed one sulphate group. Negative FAB mass spectra of the glycolipid confirmed these results, showing a molecular ion at $\mathrm{m} / \mathrm{z}$ $1055\left(\mathrm{M}-\mathrm{H}^{+}\right)^{-}$.

Acid hydrolysis of the desulphated derivative gave 2,3di- $O$-phytanyl-sn-glycerol in the $\mathrm{CHCl}_{3}$ phase and glucose and mannose in the $\mathrm{H}_{2} \mathrm{O}$ phase. The sugars and isopranoid diether were identified in TLC, HPLC and ${ }^{13} \mathrm{C}$ NMR by comparison with authentic samples. The absolute configuration of the two hexoses was established, after HPLC purification, by determination of their rotation $\left([\alpha]_{D}=+52^{\circ}\right.$ for glucose and $+15^{\circ}$ for mannose). A 1:1 molar ratio of the two hexoses was confirmed by integration of the HPLC peak areas against known concentrations.

Signals of the anomeric protons, in the ${ }^{1} \mathrm{H}$ NMR spectra of the glycolipid, at $\delta 4.78(\mathrm{~d}, J=1 \mathrm{~Hz}$, glucose) and at $\delta 4.73(\mathrm{~d}, J=1 \mathrm{~Hz}$, mannose) and the value of ${ }^{3} J_{\mathrm{H} 1-\mathrm{H} 2}$ indicate an $\alpha$ configuration for the two hexoses. These data were consistent with the value of the chemical shift of the anomeric carbons in the ${ }^{13} \mathrm{C}$ NMR spectra runs in deuterobenzene- $\mathrm{d}_{6} / \mathrm{C}^{2} \mathrm{H}_{3} \mathrm{O}^{2} \mathrm{H}(1: 1, \mathrm{v} / \mathrm{v})$ : $\mathbf{9 7 . 3 0}$ for mannose and $\mathbf{9 4 . 1 4}$ for glucose. In Table 1 are reported the assignments of the signals in the ${ }^{13} \mathrm{C}$ NMR spectrum of the glycolipid. Most of the signals were assigned by comparison with signals derived from the closely related glycolipid of $\mathrm{Hb}$. saccharovorum (Lanzotti et al., 1988). The two signals at 61.5 and 61.8 assigned to the $\mathrm{C} 6$ of the glucosyl and mannosyl residues, respectively, indicate that sulphate in this glycolipid is not linked at $\mathrm{C} 6$ of the mannosyl moiety as reported for the glycolipid of $\mathrm{Hb}$. saccharovorum. However, other signals of the carbohydrate moieties are tentatively assigned and could be reversed.

Permethylation of intact sulphated glycolipid and of its desulphated derivative and successive acid methanolysis gave methyl 2,3,6-trimethyl glucose in both cases, and methyl 3,4,6-trimethyl mannose for sulphated glycolipid and methyl 2,3,4,6-tetramethyl mannose for its desulphated derivative.

These data confirm an $\alpha$-D-mannopyranosyl-(1-4)- $\alpha-$
Table 1. ${ }^{13} \mathrm{C}$ NMR assignments of the sulphated glycolipid of $\mathrm{Hb}$. sodomense

\begin{tabular}{lll}
\hline \hline & & \\
Position & Carbon atom & $\begin{array}{c}\text { Chemical } \\
\text { shift } \\
(\delta, \text { p.p.m.) }\end{array}$ \\
\hline Isopranoid & 1 & $68 \cdot 5$ \\
chains & $1 \mathrm{a}$ & $70 \cdot 7$ \\
& 2 & $37 \cdot 1$ \\
& $2 \mathrm{a}$ & $37 \cdot 4$ \\
& 3 & $30 \cdot 5$ \\
& $3 \mathrm{a}$ & $30 \cdot 6$ \\
& $4,6,8,10,12$ & $38 \cdot 2$ \\
& 5 & $24 \cdot 9$ \\
& 7,11 & $33 \cdot 2$ \\
& 9 & $24 \cdot 8$ \\
& 13 & $25 \cdot 2$ \\
& 14 & $40 \cdot 0$ \\
& 15 & $28 \cdot 5$ \\
& 16 & $20 \cdot 0$ \\
Glycerol & 17,18 & $20 \cdot 1$ \\
& 19,20 & $22 \cdot 9$ \\
& & $23 \cdot 0$ \\
Glucosyl & 1 & $71 \cdot 5$ \\
& 2 & $78 \cdot 4$ \\
& 3 & $69 \cdot 6$ \\
& 1 & $96 \cdot 9(97 \cdot 14)$ \\
& 2 & $72 \cdot 0$ \\
3 Mannosyl & 3 & $72 \cdot 2$ \\
& 4 & $77 \cdot 1$ \\
& 5 & $70 \cdot 5$ \\
& 6 & $61 \cdot 5$ \\
& 1 & $96 \cdot 9(97 \cdot 30)$ \\
& 2 & $77 \cdot 6$ \\
& 5 & $71 \cdot 8$ \\
& 6 & $67 \cdot 7$ \\
& & $73 \cdot 4$ \\
& & $61 \cdot 8$ \\
\hline
\end{tabular}

* Chemical shifts in parentheses refer to spectra performed in deuterobenzene- $\mathrm{d}_{6} / \mathrm{C}^{2} \mathrm{H}_{5} \mathrm{O}^{2} \mathrm{H}$.

D-glucopyranosyl sequence and indicate that sulphate is linked to the $\mathrm{C} 2$ of the mannose, establishing the structure of the glycolipid as 2,3-di- $O$-phytanyl-1- $O$ [mannopyranosyl-1(2-sulphate)- $\alpha$-D- $(1 \rightarrow 4)$-glucopyranosyl- $\alpha$-D-]-sn-glycerol (Fig. 2).

This is the first report of a halobacterial glycolipid that is not derived from the core mannosyl $\alpha(1 \rightarrow 2)$-glucosyl diphytanyl glycerol described by Kamekura \& Kates (1989). The glycolipid is unusual on two counts: firstly, it is a mannosyl $\alpha-(1 \rightarrow 4)$-glucosyl diphytanyl glycerol sulphate; secondly, the sulphate residue is linked to the $\mathrm{C} 2$ of the mannose residue rather than the $\mathrm{C} 3$ or $\mathrm{C} 6$ (Kamekura \& Kates, 1989). We propose to designate this lipid as S-DGD-3 to distinguish it from the S-DGD-1 glycolipid of $\mathrm{Hb}$. saccharovorum and other strains. An uncharacterized unsulphated glycolipid designated GL-1 by Kamekura \& Kates (1989), possessed in trace amounts by Haloarcula spp., has in the past been referred 


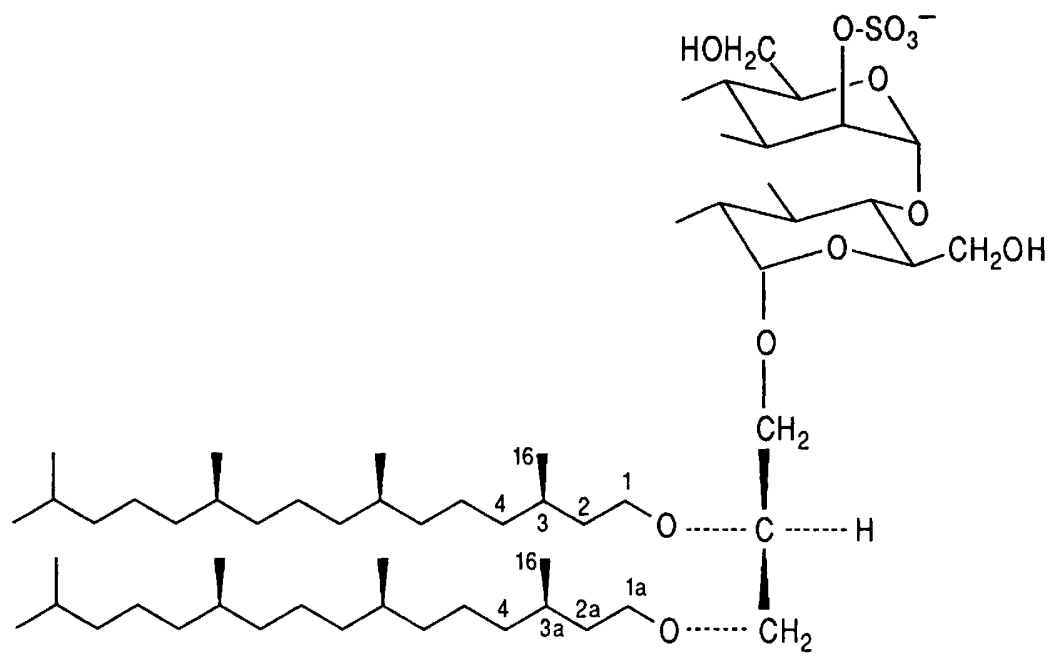

Fig. 2. 2,3-di-O-phytanyl-1-O-[mannopyranosyl-(2-sulphate)- $\alpha$-D-(1 $\rightarrow 4)$-glucopyranosyl- $\alpha$-D-]-sn-glycerol (S-DGD-3).

to as DGD-2 (Torreblanca et al., 1986; Grant \& Larsen, $1989 a$ ). This glycolipid may have the same structure as the unsulphated form of S-DGD-3. Detailed analyses will be necessary to settle this point and to establish if SDGD-3 is different from the uncharacterized sulphated glycolipid, designated S-DGD-2, isolated from another halobacterium described by Kamekura \& Kates (1989).

These results reinforce the idea that $H b$. sodomense is distinct from $H b$. saccharovorum, although both have similar polar lipid profiles (PG, PGP, PGS, glycolipid) distinct from any of the other halobacterial groups (Grant \& Larsen, 1989a). There is no doubt that $H b$. sodomense and $H b$. saccharovorum (probably together with $\mathrm{Hb}$. trapanicum) should be reclassified. The real question is whether they together constitute a taxon at genus level, or whether $H b$. sodomense is sufficiently different to merit separate reclassification at that level. In view of the weight given to lipid composition and structure in the current classification (Grant \& Larsen, $1989 a$ ), separate status for $H b$. sodomense merits serious consideration. It is of interest that in the recent description of a psychrophilic halobacterium (Franzmann et al., 1988), oligonucleotide catalogue data indicated that $H b$. saccharovorum was its closest relative amongst those halobacteria so far catalogued, whereas $\mathrm{Hb}$. sodomense was much less closely related although more closely related than selected examples from the genera Haloarcula, Haloferax, Halococcus, Natronococcus and Halobacterium sensu strict.

We are currently attempting to sequence the $16 \mathrm{~S}$ rRNA of $\mathrm{Hb}$. sodomense, with the aim of establishing its taxonomic ranking unequivocally.

We thank Mr S. Zambardino for running NMR spectra and Mr E. Pagnotta and $\mathrm{Mr}$ G. Pinch for technical assistance.

\section{References}

Conway de Macario, E., Konig, H. \& Macario, A. J. L. (1986). Immunological distinctness of archaebacteria that grow in high salt. Journal of Bacteriology 168, 425-427.

DHAR, N. M. \& AltekAR, W. (1986). Distribution of class I and class II fructose biphosphate aldolases in halophilic archaebacteria. FEMS Microbiology Letters 35, 177-181.

Franzmann, P. P., Stackebrandt, E., Sanderson, K., Volkmann, J. K., Cameron, D. E., Stevenson, P. L., McMeekin, T. A. \& BURTON, H. R. (1988). Halobacterium lacusprofundii sp. nov., a halophilic bacterium isolated from Deep Lake, Antarctica. Systematic and Applied Microbiology 11, 20-27.

Grant, W. D. (1989a). Genus Natronobacterium. In Bergey's Manual of Systematic Bacteriology, vol. 3, pp. 2230-2232. Edited by J. T. Staley, M. P. Bryant, N. Pfennig \& J. G. Holt. Baltimore: Williams \& Wilkins.

Grant, W. D. (1989b). Genus Natronococcus. In Bergey's Manual of Systematic Bacteriology, vol. 3, pp. 2232-2233. Edited by J. T. Staley, M. P. Bryant, N. Pfennig \& J. G. Holt. Baltimore: Williams \& Wilkins.

Grant, W. D. \& LARSEN, H. (1989a). Extremely halophilic archaeobacteria. Order Halobacteriales ord. nov. In Bergey's Manual of Systematic Bacteriology, vol. 3, pp. 2216-2219. Edited by J. T. Staley, M. P. Bryant, N. Pfennig \& J. G. Holt. Baltimore: Williams \& Wilkins.

Grant, W. D. \& LaRSEN, H. (1989b). Genus Haloarcula. In Bergey's Manual of Systematic Bacteriology, vol. 3, pp. 2224-2226. Edited by J. T. Staley, M. P. Bryant, N. Pfennig and J. G. Holt. Baltimore: Williams \& Wilkins.

Grant, W. D. \& Larsen, H. (1989c). Genus Haloferax. In Bergey's Manual of Systematic Bacteriology, vol. 3, pp. 2226-2228. Edited by J. T. Staley, M. P. Bryant, N. Pfennig \& J. G. Holt. Baltimore: Williams \& Wilkins.

Grant, W. D. \& Ross, H. N. M. (1986). The ecology and taxonomy of halobacteria. FEMS Microbiology Reviews 39, 9-15.

KAMEKURA, M. \& KaTES, M. (1989). Lipids of halophilic archaebacteria. In Halophilic Bacteria, vol. II, pp. 25-54. Edited by F. Rodriguez-Valera. Boca Raton: CRC Press.

KaTES, M. (1986). Techniques of Lipidology, 2nd edn, pp. 241-242. Amsterdam: Elsevier.

Lanzotti, V., Nicolaud, B., Trincone, A. \& Grant, W. D. (1988). The glycolipid of Halobacterium saccharovorum. FEMS Microbiology Letters 55, 223-228. 
Larsen, H. \& Grant, W. D. (1989). Genus Halobacterium. In Bergey's Manual of Systematic Bacteriology, vol. 3, pp. 2219-2224. Edited by J. T. Staley, M. P. Bryant, N. Pfennig \& J. G. Holt. Baltimore: Williams \& Wilkins.

Lodwick, D., Ross, H. N. M., Harris, J. G., Almond, J. W. \& GRANT, W. D. (1986). dam methylation in archaebacteria. Journal of General Microbiology 132, 3055-3059.

Oren, A. (1983). Halobacterium sodomense sp. nov., a Dead Sea halobacterium with an extremely high magnesium requirement. International Journal of Systematic Bacteriology 33, 381-386.

Ross, H. N. M. \& Grant, W. D. (1985). Nucleic acid studies on halophilic archaebacteria. Journal of General Microbiology 131, 165-173.
Torreblanca, M., Rodriguez-Valera, F., Juez, G., Ventosa, A., KamekurA, M. \& Kates, M. (1986). Classification of nonalkaliphilic halobacteria based on numerical taxonomy and polar lipid patterns and description of Haloarcula gen. nov. and Haloferax gen. nov. Systematic and Applied Microbiology 8, 89-99.

WAGNER, H. \& SeligmanN, O. (1973). Mass spectrometry of flavonoid $O$-glycosides. Tetrahedron 29, 3029-3034.

YahaRA, S., Kasai, R. \& Tanaka, O. (1977). New dammarane type saponins of leaves of Panaxjaponicus Mayer. 1. Chikusetsusaponins $\mathrm{L}_{5}, \mathrm{~L}_{9}$, and $\mathrm{L}_{10}$. Chemical and Pharmacological Bulletin 25, 2041-2047. 